\title{
A Conexão da Gestão com a Política Nacional de Humanização da Saúde: a Experiência Desenvolvida no Hospital Municipal Odilon Behrens/Belo Horizonte-Mg
}

\author{
Miranda, Valéria dos Santos Noronha \\ Universidade Federal do Recôncavo da Bahia — valerianoronha@gmail.com
}

Introdução: o Hospital Odilon Behrens localizado em Minas Gerais possui a PNH implantada desde 2003 respeitando os seus princípios, diretrizes e o conjunto de dispositivos institucionais para a operacionalização da política, constituindo-se um marco no que tange ao modelo de atenção e humanização da saúde. o presente estudo procurou contextualizar a PNH no âmbito do Sistema Único de Saúde - SUS, identificando os seus elementos históricos, os avanços e desafios contidos nas suas proposições. Ainda, buscase aprofundar a discussão em torno dos seus dispositivos institucionais. em especial, o trabalho procurou examinar a conexão da gestão com a política, introduzindo um debate acerca da gestão hospitalar do Odilon Behrens, de suas inovações e de sua relação com a (re)organização dos processos de trabalho em saúde. Objetivos: Descrever e analisar as condições políticas e organizacionais que possibilitaram as mudanças feitas a partir da PNH no âmbito do Hospital Odilon Behrens situado no Município de Belo Horizonte em Minas Gerais. Métodos: como procedimentos metodológicos foram utilizadas as pesquisas qualitativa e documental com a adoção de entrevistas (semi-estruturadas) realizadas com os formuladores da política e com os gestores do hospital, identificando as possibilidades e limites no processo de implantação e continuidade da política em uma Unidade Hospitalar. Resultados: Os principais resultados dessa pesquisa apontaram que existe uma relação intrínseca e dinâmica entre gestão e a $\mathrm{PNH}$. a gestão participativa favorece a incorporação da política mais facilmente em um hospital que já tenha essa cultura. em contrapartida, a PNH produz mudanças concretas nos mecanismos de gestão de um hospital, consequentemente, modificando as práticas de atenção. Conclusões: Concluise que para dar conta de produzir inovações na organização do cuidado e na formação, enfrentando a resistência que elas implicam, são necessárias novas referências e dispositivos para a gestão em saúde sugeridos a partir da $\mathrm{PNH}$. a $\mathrm{PNH}$ não é uma política abstrata e nem uma "panacéia romântica", concretiza-se no âmbito do SUS, produzindo inovações importantes no sistema de saúde.

Miranda, Valéria dos Santos Noronha. A Conexão da Gestão com a Política Nacional de Humanização da Saúde: a Experiência Desenvolvida no Hospital Municipal Odilon Behrens/Belo Horizonte-Mg. In: Anais do Congresso Internacional de Humanidades \& Humanização em Saúde [= Blucher Medical Proceedings, num.2, vol.1]. São Paulo: Editora Blucher, 2014. ISSN 2357-7282

DOI 10.5151/medpro-cihhs-10211 